\title{
Functions of Oral History from Inheritor of Intangible Cultural Heritage in Cultural Heritage Protection \\ Jia-Qi MEI
}

Art Institute of Jiujiang University, Jiangxi Province, China

audiomjq@163.com,71290314@qq.com

Keywords: intangible cultural heritage; inheritor; oral history

\begin{abstract}
Oral history of intangible cultural heritage is a method of studying the history by collecting and using oral historical data. Furthermore, it is a way to research history by the well-prepared interviewer through transcript, sound recording and other methods to collect and sort the oral memories as well as the viewpoints with historical significance.
\end{abstract}

\section{Introduction}

Intangible cultural heritage is generated under specific historical conditions and geographical environment, which has been inherited to the current age over years among the culture and tradition formed in the long history of human society. It is the cultural accumulation of different ethnic groups or different nations, and an integral part of human civilization. They are carrying the rich history, reflecting the changes of culture and traditions, recording the evolution information between tradition and modern. It represents the fresh culture and the original cultural genes. Intangible cultural heritage has accumulated the production and development level, social structure, life style, morality custom and taboos of different historical periods, having great historical value.

The term of oral history was created formally in the 1940s. In brief, oral history refers to history with sounds, which is a method to record people's special memories and life experiences.

Louis - Starr, the colleague of founder of the oral history Alan - Nevins and the academic successor, said that dictating history is to record the original data with preservation value and having not been obtained till now that dictated by people through well-prepared interview with recorder as a tool.

Oral history of inheritor of intangible cultural heritage is the record of a person's life experience, historical experience and emotional world; meanwhile, it is the vivid record of historical events of a certain era. And the oral history researchers' taking down of interviewee's dictating of various historical events through the interview has become the first important thing of oral history. Obviously, the purpose of intangible cultural heritage's inheritor to dictate history is to rebuild the interviewee's life history, rebuild the historical events and memories, and to learn about that era and things happened in that era by virtue of interviewee's personal experience and the historical experience.

The inheritor of intangible cultural heritage uses oral history as research method, which includes double meaning of "dictating" and "history". In fact, how will the researchers integrate the oral research concept, historical event and ordinary people's personal experience into a same research? In other words, study of oral history is not just a nostalgic way, but also a method to learn about the relationship between the past people, event and object and that in the current times via oral interview.

The research on oral history dictated by intangible cultural heritage's inheritor has the following five features:

The dictating made by inheritor of intangible cultural heritage can correct the text bias, which is vivid and is especially suitable for the expression of various relations in human life.

The oral history of inheritor of intangible cultural heritage focuses on reproduction of history, but not simply interpreting history.

The oral historiography method used in oral history of inheritor of intangible cultural heritage is a 
unique approach. The oral method is to combine the fieldwork and the study work, having a set of internationally accepted norms and procedures.

Study work of oral history of inheritor of intangible cultural heritage can be diversified, which can be arranged in advance no matter it is people-centered or theme-centered.

The research on oral history of inheritor of intangible cultural heritage is an academic way with modern characters, which can propose challenge against the discourse monopoly of upper academic cycle, because the ordinary interviewees and visitors can become a historical role.

The protection of inheritor of intangible cultural heritage is an integral part of the intangible cultural heritage protection, the core content of intangible cultural heritage protection, and the important component of inheritance and development of intangible cultural heritage. In essence, the protection of intangible cultural heritage's inheritor is the soul of intangible cultural heritage protection, is the honor and respect expressed for the living culture. Therefore, the research on oral history of inheritor of intangible cultural heritage is of the important and irreplaceable significance and value.

\section{Inheritor is the Soul of Intangible Cultural Heritage Items}

Intangible cultural heritage exists in the form of a living state, and its living lies in its close combination with people's lives, and it is a culture of living state; and its state of living, an important sign, is the human activity. Among them, its soul exists in the inheritor's activity. The inheritor is the soul of intangible cultural heritage items. The protection of inheritor of intangible cultural heritage is equivalent to the protection of soul of intangible cultural heritage, which cannot be replaced by other protection methods. To this end, the recording of inheritor's activity, or retaining the inheritor's figure, is an important task.

\section{Inheritor is the Transmitter of the History of Nation without Written Words}

There are a lot of histories without written words in human history. The history of those nations without written words is almost transmitted orally. And such method is mainly completed by the local inheritors in terms oral literature, especially the epic and the like. They are the transmitters of national history, having extremely high value for the research on national history and culture.

\section{Inheritor is the Inheritor and Creator of Techniques}

Intangible cultural heritage is the inheritor of intangible cultural heritage, which is very important itself. At the same time, in many cases, they are the creator, improver, transmitter and developer of intangible cultural heritage techniques.

As for the living state of intangible cultural heritage, it is common to inherit, innovate and even create. Therefore, only such creation and improvement can adapt to or meet the development needs of the times. Therefore, the inheritor of intangible cultural heritage is not only the inheritor of techniques, but also the creator of intangible cultural heritage with same type and even different types. Their role is very special, which shall be protected and recorded.

\section{Inheritor Carries Forward both the Techniques and Culture}

The inheritor of intangible cultural heritage survives by obtaining techniques, and carrying forwarding techniques is their responsibility. But, while they are inheriting techniques, the function of transmitting culture is also granted to them. The reason is that the activities or products of intangible cultural heritage always carry the distinctive national or local cultural characteristics. The transmission of such activities or products also means the transmission of such culture or characteristic culture. 


\section{Protection of Inheritor is the Guarantee of Special Culture Continuity}

Inheritor of intangible cultural heritage often retains some special cultural patterns or techniques, which play a role that cannot be replaced by other protection methods in the process of inheriting such special cultural patterns. It is the existence of inheritor that enables some traditional techniques, especially the unique techniques, to be preserved for a long term. Though the inheritor may not be known widely, the protection of inheritor can make some culture with national characteristics be carried forward better.

\section{References:}

[1]Wan Ping. Oral History of Old Artist [M]. People's Publishing House. 2014

[2]Li Xiangping, Wei Yangbo. Research Method of Oral History [M]. Shanghai People's Publishing House. 2010

[3]Ding Yizhuang, Wang Run. Oral History Textbook [M]. Peking University Press. 2011

[4]Yuan Li, Gu Jun. Oral History of Inheritor of Beijing Intangible Cultural Heritage [M]. Capital Normal University Press. 2015

[5]Chen Huawen. Retain the Inheritor [M]. Zhejiang Gongshang University Press. 2013

[6] Liao Mingjun, Yang Minkang. Traditional Music and Intangible Cultural Heritage Protection [J]. Ethnic Arts Quarterly. 2008(01)

[7] Dai Hong. Traditional Music Inheritor from the Perspective of Intangible Cultural Heritage Protection [J]. Journal of Xinghai Conservatory of Music 2008(01)

[8] Feng Guangyu. Intangible Cultural Heritage Protection and Inheritance of Traditional Chinese Music [J]. Journal of Shenyang Conservatory of Music, 2006(02)

[9] Pan Gang. Principle and Method of Oral History of Intangible Cultural Heritage's Inheritor under Folklore Context [J]. Jounral of Yunnan Normal University. 2015(03)

[10] Liu Xinyi. Current Situation of Construction of Oral History Database of Guizhou Intangible Cultural Heritage’s Inheritor and the Assumption [J]. Guizhou Normal University.2013(08) 